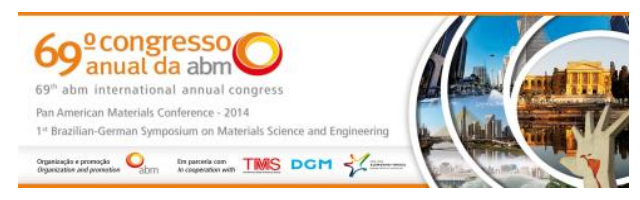

Tema: Gestão de Manutenção

\title{
AUMENTO DA DISPONIBILIDADE FÍSICA DAS PÁS MECÂNICAS CATERPILLAR 994 DO COMPLEXO MARIANA*
}

\section{Resumo}

\author{
Erika Baêta e Souza' \\ Leandro Fonseca Pessoa ${ }^{2}$ \\ Maximiliano Martins de Souza ${ }^{3}$
}

Essa frota é fundamental em função da flexibilidade de produção. No entanto, o produto da manutenção é a disponibilidade física (DF), que é o tempo disponível para o equipamento operar. Assim, desenvolveu-se um trabalho de seis sigma voltado para a disponibilidade física (DF) da frota, que não estava no patamar esperado. $\mathrm{O}$ trabalho foi desenvolvido através de ferramentas de análise e solução de problemas, no período de Jan/12 a Ago/12. A DF média da frota era $68,5 \%$ sendo o benchmark interno de $72 \%$. As ocorrências de parada foram agrupadas por sistemas utilizando o critério de similaridade. Após isso foram utilizadas ferramentas de priorização dos focos mais relevantes encontrados. Para estes focos foi feita análise de comportamento no tempo e variabilidade com intuito de encontrar as causas fundamentais para ocorrência dos eventos. As causas foram classificadas e priorizadas e as ações foram então definidas e implantadas. Foram monitorados os indicadores MTBF, DF e considerado o aspecto financeiro. Estabeleceu-se uma rotina de gestão e padronização de processo como forma de alcançar o resultado. Ao fim do trabalho, foram plantadas as sementes dos bons resultados colhidos desde então, chegando a DF de $74,1 \%$.

Palavras-chave: DF; 994.

\section{INCREASE THE PHYSICAL AVAILABILITY OF MECHANICAL SPADES CATERPILLAR 994 IN MARIANA COMPLEX}

\begin{abstract}
This fleet is critical due to the flexibility of production. However, maintenance is the product of the physical availability (DF), that the time available to operate the equipment. Thus, it has developed a job six sigma facing physical availability (DF) of the fleet, which was not in the expected level. The work was developed through analysis tools and troubleshooting, between Jan/12 to Aug/12. The average DF fleet was $68.5 \%$ and the internal benchmark of $72 \%$. Instances of arrest were grouped by sistesmas using the similarity criterion. After this prioritization of the most important foci were found tools utilidas. For these outbreaks behavior analysis in time and variability in order to find underlying causes for the occurrence of events was taken. The causes were classified and prioritized and actions were then defined and deploye. The MTBF, DF indicators were monitored and considered the financial aspect. Established a routine management and standardization process in order to achieve the result. After work, were planted the seeds of good results obtained since then, reaching $74.1 \%$ of DF.
\end{abstract}

Keywords: PA; 994.

\footnotetext{
Engenheira de Produção, Engenheira, Vale SA, Mariana, MG, Brasil.

Técnico Mecânico, Orientador técnico, Vale SA, Mariana, MG, Brasil.

Engenheiro Mecânico, Supervisor, Vale SA, Mariana, MG, Brasil.
}

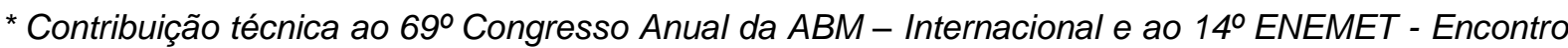
Nacional de Estudantes de Engenharia Metalúrgica, de Materiais e de Minas, 21 a 25 de julho de 2014, São Paulo, SP, Brasil.
} 


\section{INTRODUÇÃO}

O presente trabalho tem como objetivo mostrar a aplicabilidade da metodologia seis sigma em um caso prático realizado na empresa Vale SA.

O seis sigma é um programa que busca a redução das ineficiências como falhas, erros, desperdícios, retraballhos e visa à melhoria drástica dos resultados empresariais. E baseado na aplicação de uma metodologia estruturada e em decisões orientadas por análise de dados e fatos. Possui este nome, pois todos os processos podem ser classificados por um nível sigma de qualidade, esta classificação depende do percentual de defeitos ou não conformidades que estes produzem. Para tal classificação utiliza-se a escala Seis Sigma (Tabela 1).

Tabela 1. Escala Sigma

Dois sigma

Três sigma

Quatro sigma

Cinco sigma

Seis sigma
308.537

66.807

6.210

233

3,4

Fonte: Adaptada de [1].

O projeto realizado foi de grande importância para a empresa uma vez que a frota de pás mecânicas 994 é uma das mais importantes para o processo produtivo e apresentava uma disponibilidade física (DF) aquém do necessário. Podemos ainda verificar o alcance do resultado acima da meta do projeto (valor orçado) o que comprova o sucesso do projeto.

\section{MATERIAIS E MÉTODOS}

Os materiais e métodos utilizados foram orientados através de consultoria realizada pelo Instituto de Desenvolvimento Gerencial (INDG). A metodologia utillizada no projeto seis sigma foi o PDCA desdobrado em onze fases conforme pode ser visualizado na Figura 1 abaixo.

* Contribuição técnica ao 69 Congresso Anual da ABM - Internacional e ao 14ํㅡㄹ ENEMET - Encontro Nacional de Estudantes de Engenharia Metalúrgica, de Materiais e de Minas, 21 a 25 de julho de 2014, São Paulo, SP, Brasil. 

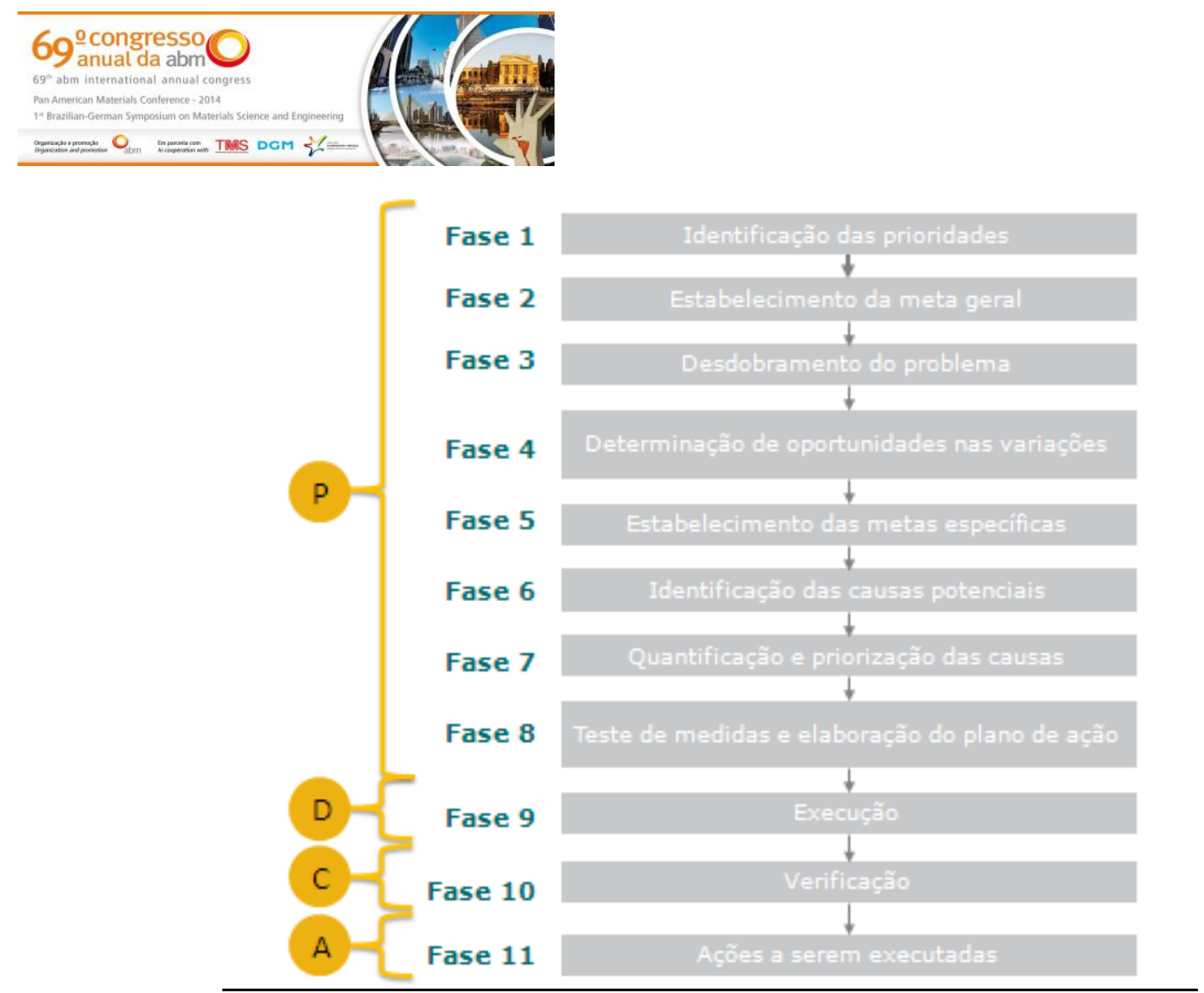

Figura 1. As onze fases do projeto.

As ferramentas utilizadas no projeto em conformidade com o método serão descritas a seguir.

\subsection{Gráfico de Colunas e Linhas}

Utilizado primeiramente a fim de identificas as prioridades (Fase I), ou seja, qual o problema seria definido para realizar o projeto elaboramos o gráfico de colunas e linhas, onde a coluna representava a DF realizada por cada frota de responsabilidade da gerência, em ordem de importância para o processo produtivo, e a linha o valor orçado para aquela frota. Com este gráfico definimos então que a frota que possuía maior GAP em relação ao orçado era a frota de PC4000, no entanto esta era uma frota nova e composta por apenas dois equipamentos e a segunda era a frota CAT994 alvo do nosso projeto uma vez que possuía sete equipamentos e por ser estratégica para cumprimento da produção já que permite flexibilidade.

Este mesmo gráfico foi também utilizado no estabelecimento da meta geral (Fase II) com o objetivo de verificar se a baixa DF era um problema pontual (de um único equipamento que compõe a frota) ou genérico (da frota como um todo) e verificouse que o problema era da frota.

$\mathrm{Na}$ fase $\mathrm{X}$ tambem fez-se uso deste gráfico para verificar o cumprimento das metas específicas.

\subsection{Gráfico Sequencial}

O gráfico sequencial foi utilizado para analisar o comportamento do indicador DF inicialmente para os anos de 2010 e 2011, histórico para início do projeto (Fase II), e posteriormente para os anos 2012, ano no qual foi iniciado o projeto, e 2013, para mostrar a sustentabilidade do resultado pós projeto (Fase $\mathrm{X}$ ).

\footnotetext{
* Contribuição técnica ao 69ํ Congresso Anual da ABM - Internacional e ao 14ํㅡㄹ ENEMET - Encontro Nacional de Estudantes de Engenharia Metalúrgica, de Materiais e de Minas, 21 a 25 de julho de 2014, São Paulo, SP, Brasil.
} 


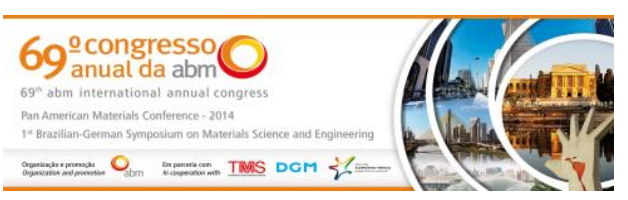

\subsection{Perfil de Perdas}

Para o desdobramento e estratificação do problema (Fase III) fez-se uso do perfil de perdas onde classificados cada parada dos equipamentos em sistema (arrefecimento, hidráulico, estrutura...), conjunto (radiador, centro, balança...) e item (vazamento, folga, trinca...) que compõem estes equipamentos.

\subsection{Diagrama de Árvore}

O diagrama de árvore foi utilizado para identificar os focos do problema (Fase III), ou seja, quais os sistemas, conjuntos e itens que afetam negativamente a DF e que devem ser priorizados no projeto para que possamos alcançar a meta proposta.

\subsection{Teste de Normalidade}

Para utilização das ferramentas estatísticas de forma correta é necessário avaliar se os dados do projeto seguem ou nao a distribuição normal, para este fim é utilizado o teste de normalidade (Fase IV) e que para o nosso projeto mostrou que os dados não são normais, isto é não seguem a distribuição normal.

\subsection{Box Plot}

Com o objetivo de avaliar a variabilidade do fenômeno que gera cada problema crítico identificando as oportunidades em cada um dos focos priorizados (Fase IV) fizemos uso da ferramenta Box Plot que permite visualizar a presença de causas especiais (variação não habitual inesperada, problema localizado), causas comuns (fazem parte do universo do projeto, problema sistêmico) e deslocamento de média. Neste projeto observamos a presença de todos estes tipos de variação. Como parte da metodologia estudamos cada uma dessas variações para assim fazer novamente o box plot e identificar qual o potencial de redução para cada um dos focos.

\subsection{Gráfico Build Up}

Com a finalidade de verificar se com o potencial de redução fornecido pelo Box Plot seria possível alcançar a meta geral do projeto fez-se uso deste tipo de gráfico assim como para mostrar que com o percentual de redução proposto para cada uma das metas específicas também atingiríamos a meta do projeto (Fase V).

\subsection{Matriz de Priorização}

Utilizada para priorizar qual o percentual de redução a ser proposto para cada um dos focos priorizados em conjunto com a opinião dos especialistas da área. Foram utilizados os critérios: Criticidade, Facilidade e Autoridade na matriz de priorização (fase V).

\section{9. Árvore de Falhas (FTA)}

Para identificar os possíveis fatores causais de cada problema específico utilizou-se a árvore de falhas que foi realizado em conjunto com todas as áreas envolvidas e através de brainstorming (Fase $\mathrm{VI}$ ).

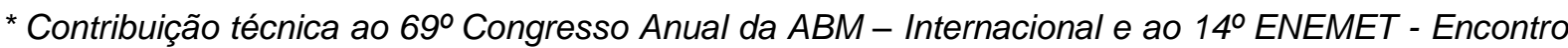
Nacional de Estudantes de Engenharia Metalúrgica, de Materiais e de Minas, 21 a 25 de julho de 2014, São Paulo, SP, Brasil. 


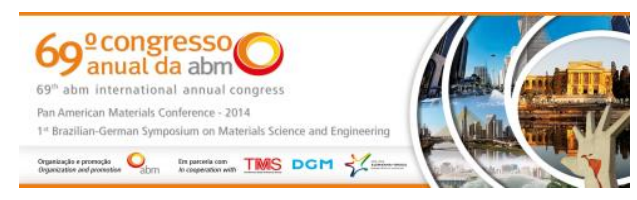

\subsection{Matriz de adequabilidade}

Para priorizar as causas de cada foco usamos a matriz de adequabilidade (Fase VII) onde comparamos se a causa levantada (condição atual) era ou não a condição ideal e a provável causa, para assim identificar a causa raiz. Para cada causa raiz utilizamos a matriz de viabilidade para dar sequência.

\subsection{Matriz de Viabilidade}

Utilizamos os critérios: viabilidade técnica, política, econômica, ambiental, econômica e continuidade para verificar se a causa raiz seria ou não tratada.

\subsection{Plano de Açao $5 \mathrm{~W} 2 \mathrm{H}$}

Para distribuir as ações utilizadas o plano de ação 5W2H (o que, quem, quando, onde, por que, quanto custa, como) (Fase VIII).

\subsection{Gráfico de Pizza}

Para acompanhar o status de cada ação proposta na Fase VIII utilizamos o gráfico de pizza.

\section{RESULTADOS E DISCUSSÃO}

Os resultados alcançados podem ser visualizados através dos gráficos abaixo.

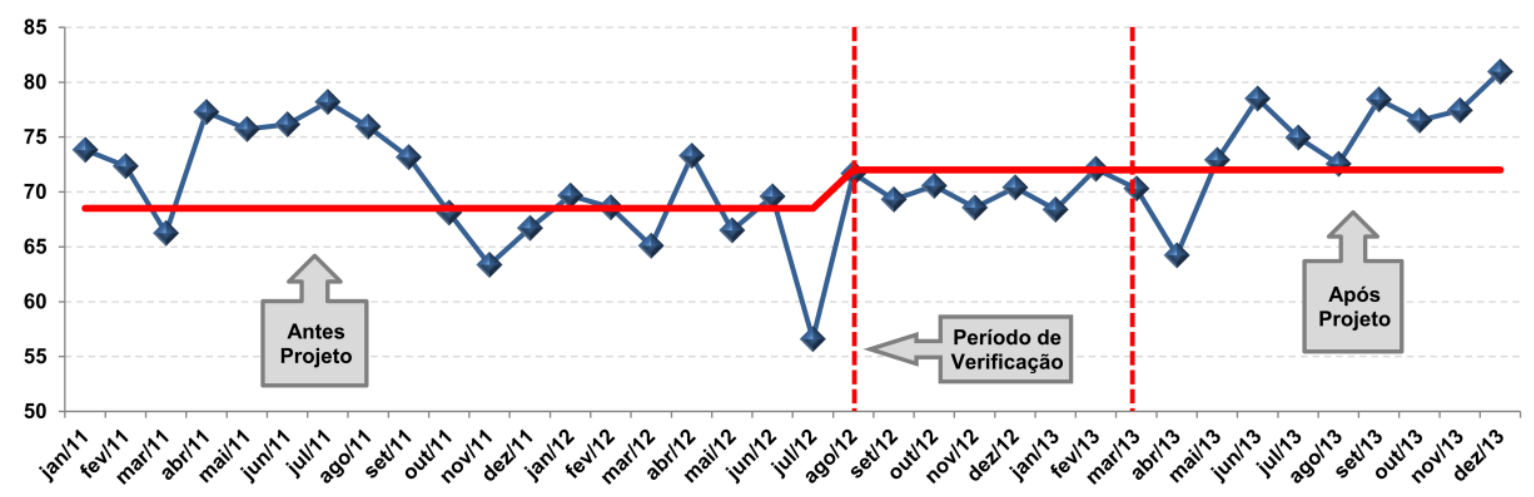

Gráfico 1. Acompanhamento da meta geral

Observa-se através do gráfico que após o projeto a DF sempre ficou acima da meta (72\%) com exceção do mês de Abril/13 onde houve uma causa especial inerente ao processo de manutenção, quebra prematura do motor diesel.

\footnotetext{
* Contribuição técnica ao 69ำ Congresso Anual da ABM - Internacional e ao 14ํㅡㄹ ENEMET - Encontro Nacional de Estudantes de Engenharia Metalúrgica, de Materiais e de Minas, 21 a 25 de julho de 2014, São Paulo, SP, Brasil.
} 


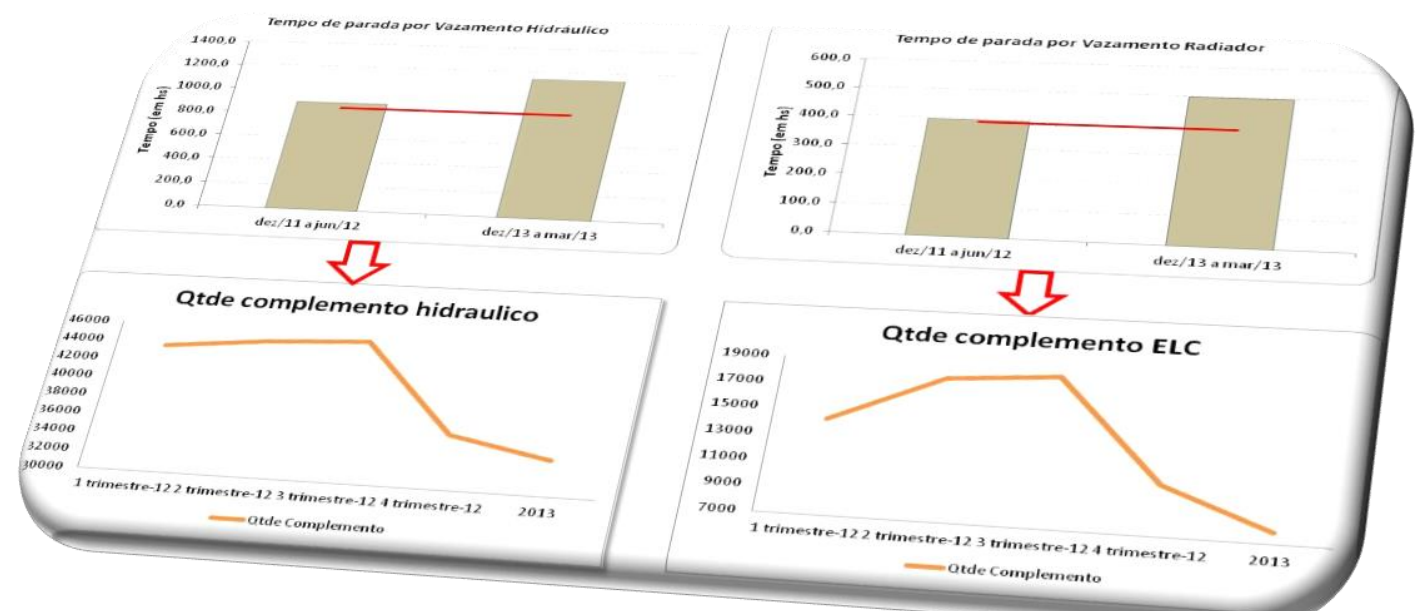

Gráfico 2. Acompanhamento metas específicas: Vazamento sistema arrefecimento e sistema hidráulico

Podemos observar para as metas específicas acima que não conseguimos a redução de DF conforme proposto, porém visualizamos a redução na quantidade de complemento do óleo hidráulico e do líquido de arrefecimento que por questão de tempo não foi convertido em redução de DF.

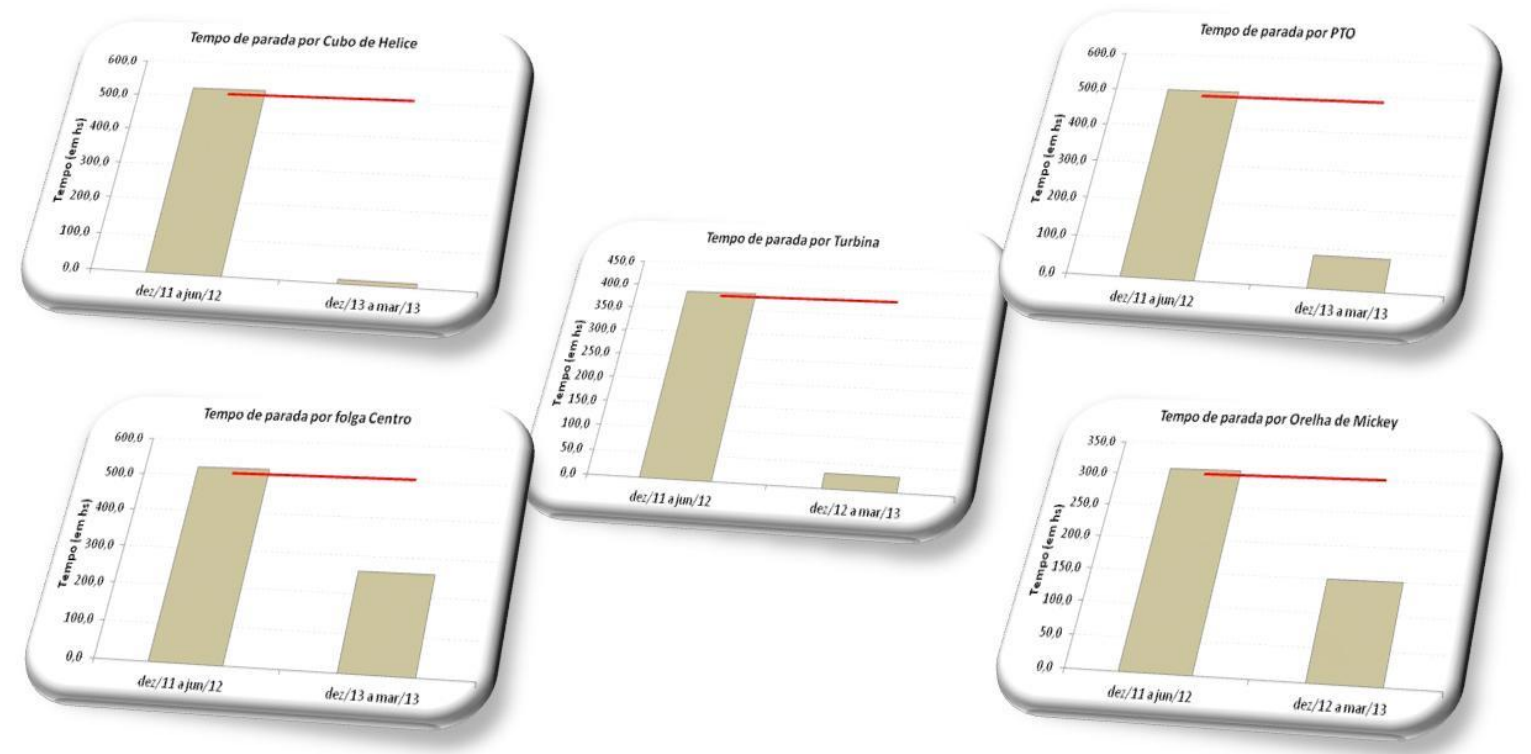

Gráfico 3. Acompanhamento metas específicas: cubo de hélice, folga no centro, orelha de mickey, turbina e PTO.

Através dos gráficos acima podemos verificar que todas essas metas específicas foram superadas.

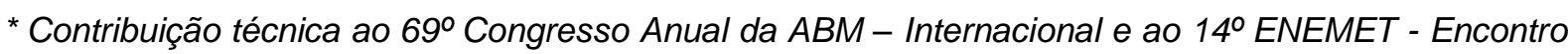
Nacional de Estudantes de Engenharia Metalúrgica, de Materiais e de Minas, 21 a 25 de julho de 2014, São Paulo, SP, Brasil. 

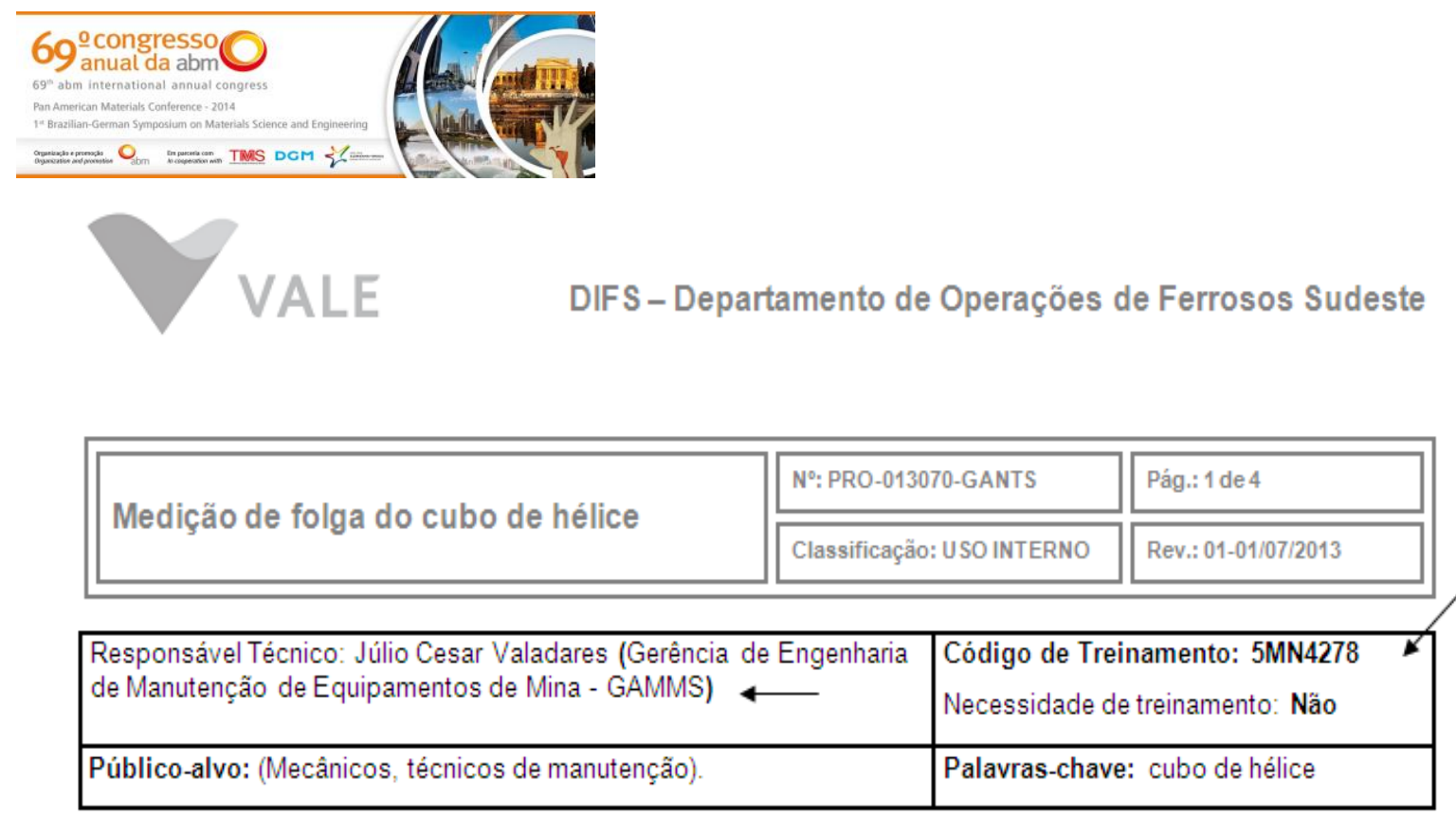

Figura 2. Elaboração procedimento - PRO: 013070 (Fonte: SISPAV).

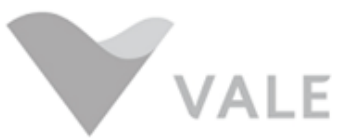

DIFS - Departamento de Operações de Ferrosos Sudeste

Troca de mangueiras do sistema hidráulico de carregadeiras CAT994

$\mathrm{N}^{\circ}:$ PRO-015858

Classificação: USO INTERNO

Pág.: 1 de 4

Rev.: 00-22/10/2012

\begin{tabular}{|l|l|}
\hline $\begin{array}{l}\text { Responsável Técnico: Edmilson Antonio (Gerência de } \\
\text { Manutenção de equipamentos de Terraplanagem e } \\
\text { Carregamento - GANTS) }\end{array}$ & $\begin{array}{l}\text { Código de Treinamento: 5QA3084 } \\
\text { Necessidade de Treinamento: Sim }\end{array}$ \\
\hline $\begin{array}{l}\text { Público-alvo: Todos os empregados da área de } \\
\text { carregadeiras 994D e 994F }\end{array}$ & Palavras-chave: hidráulico, sistema. \\
\hline
\end{tabular}

Figura 3. Elaboração procedimento - PRO:015858 (Fonte: SISPAV).

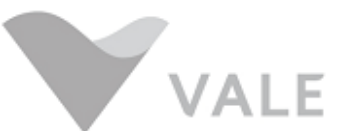

DIFS - Departamento de Operações de Ferrosos Sudeste

\begin{tabular}{|l|l|l|}
\hline $\begin{array}{l}\text { Medição de folga de centro de } \\
\text { carregadeiras CAT994 }\end{array}$ & \begin{tabular}{l|l|l|}
\hline Pág.: 1 de 9 \\
\hline Classificação: USO INTERNO 016280 GANTS
\end{tabular} \\
\hline
\end{tabular}

\begin{tabular}{|l|l|}
\hline $\begin{array}{l}\text { Responsável Técnico: Edmilson Antônio (Gerência de } \\
\text { Manutenção de equipamentos de Terraplanagem e } \\
\text { Carregamento - GANTS) }\end{array}$ & $\begin{array}{l}\text { Código de Treinamento: 5MN4146 } \\
\text { Necessidade de Treinamento: Sim }\end{array}$ \\
\hline $\begin{array}{l}\text { Público-alvo: Todos os empregados da área de } \\
\text { carregadeiras 994D e 994F }\end{array}$ & Palavras-chave: medição, centro, folga. \\
\hline
\end{tabular}

Figura 4. Elaboração procedimento - PRO: 016280 (Fonte: SISPAV).

\footnotetext{
* Contribuição técnica ao 69 Congresso Anual da ABM - Internacional e ao 14ํㅡㄹ ENEMET - Encontro Nacional de Estudantes de Engenharia Metalúrgica, de Materiais e de Minas, 21 a 25 de julho de 2014, São Paulo, SP, Brasil.
} 
Para as Figuras 2, 3 e 4 tratam-se de procedimentos operacionais elaborados como saídas do projeto para padronização e qualidade das atividades a serem executadas. Estes procedimentos foram inclusos na matriz de treinamentos dos mecânicos que atendem tal frota para garantir que todos sejam treinados antes da realização da atividade. Nas figuras 5 e 6 a seguir tais fatos podem ser verificados.

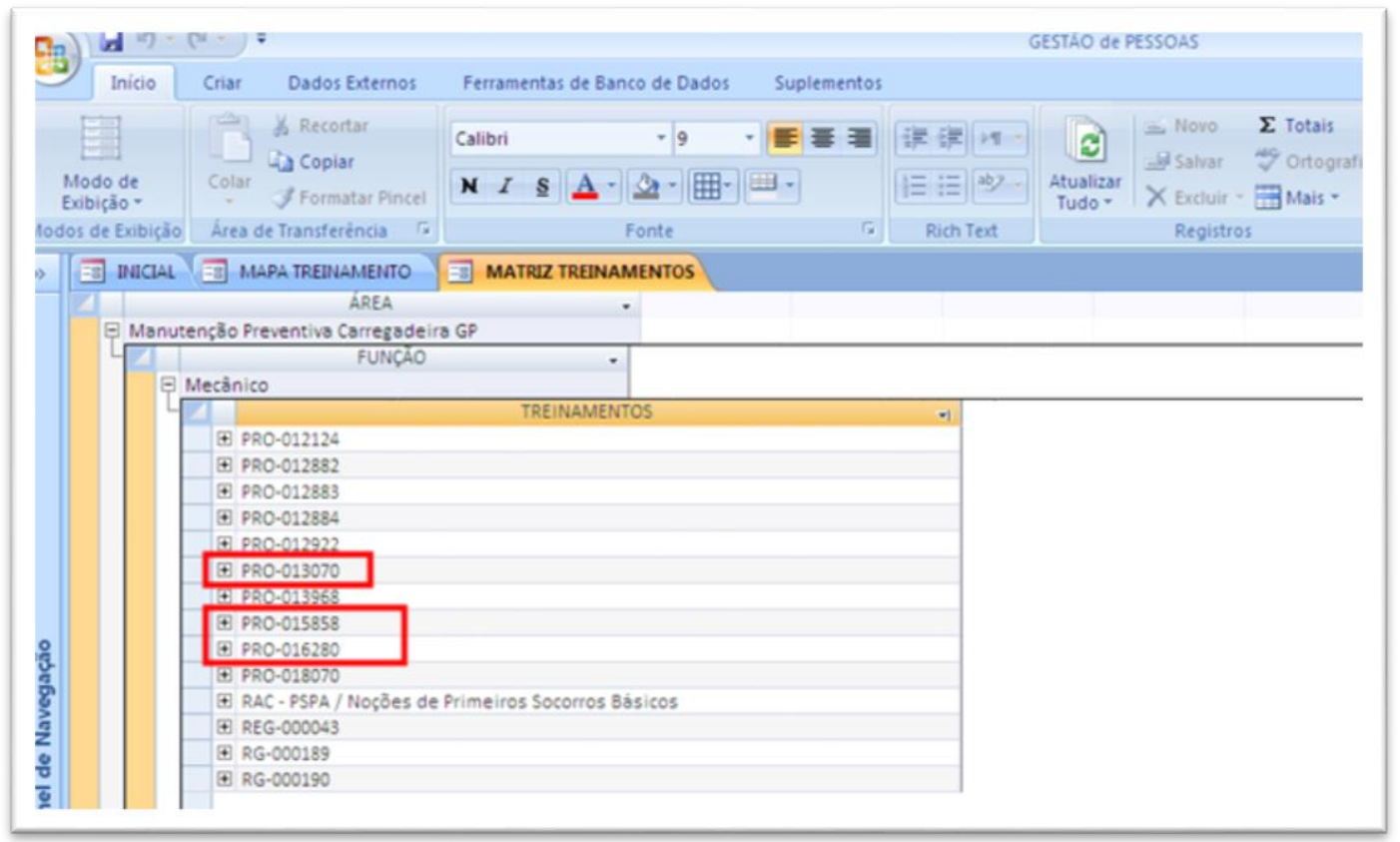

Figura 5. Inclusão na matriz de treinamento

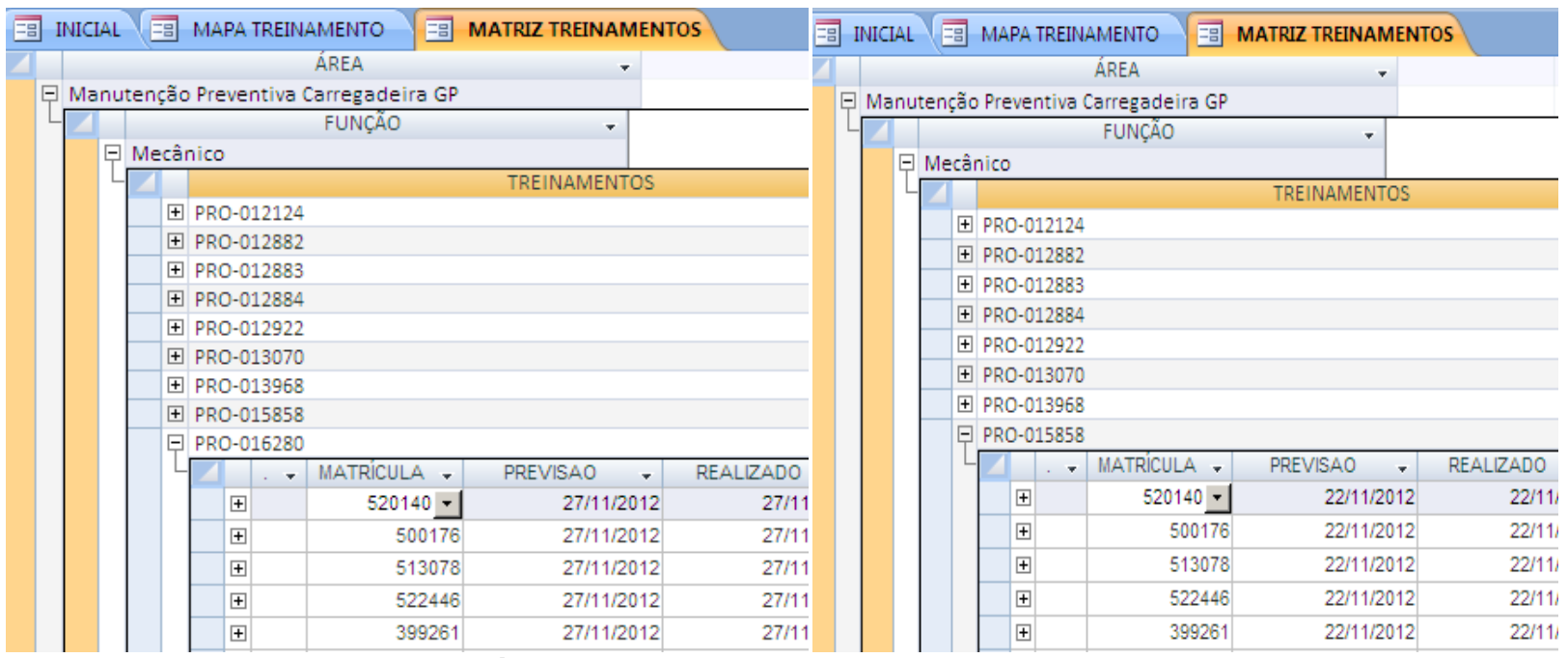

Figura 6. Treinamento dos envolvidos

\section{CONCLUSÃo}

A metodologia utilizada foi o PDCA que para este projeto foi desdobrado em onze fases.

As fases de 1 a 8 correspondem á fase P do PDCA, fase de planejamento, nesta fase definisse qual o problema a ser estudado através, neste caso, do gráfico de colunas e linhas, definição da meta geral com base em histórico (gráfico sequencial), estratificação e focalização do problema (perfil de perdas, árvore diagrama de árvores), avaliação da variabilidade do fenômeno que gera cada problema crítico

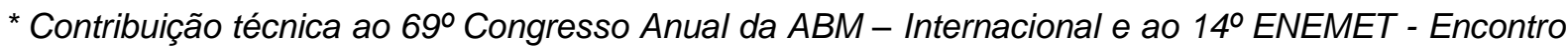
Nacional de Estudantes de Engenharia Metalúrgica, de Materiais e de Minas, 21 a 25 de julho de 2014, São Paulo, SP, Brasil. 
identificando as oportunidades em cada um dos focos priorizados (teste de normalidade, box plot), definição das metas específicas (gráfico build up, matriz de priorização), definição das causas potenciais dos focos priorizados (árvore de falhas), verificação das causas que realmente interferem do projeto (matriz de adequabilidade, matriz de viabilidade) e elaboração do plano de ação (5W2H).

Fase 9 corresponde á fase D do PDCA, fase de execução, nesta fase é realizado o acompanhamento das ações propostas e para este fim foi utilizado o gráfico de pizza.

Fase 10 corresponde á fase $\mathrm{C}$ do PDCA, fase checar, fase responsável por verificar quanto ao alcance das metas geral e específicas e validação econômica do projeto. O projeto realizado gerou uma economia de $R \$ 3.357 .343,00$ para a gerência o que contribuiu para que a meta de gasto fosse cumprida. As ferramentas utilizadas foram os gráficos sequenciais, gráficos de colunas e linhas.

Fase 11 corresponde á fase A do PDCA, fase Agir, esta fase é a responsável por padronizar todas as ações realizadas no projeto para garantir a sustentabilidade do mesmo e para isto foram elaborados procedimentos operacionais, inclusão dos mesmos na matriz de treinamento e realizado os treinamentos.

A relação entre as onze fases e o PDCA pode ser visualizado na figura 1.

O método utilizado pode ser o PDCA ou o DMAIC, porém as fases sempre serão agrupadas em planejamento, execução, check e ação ou padronização. Já em relação às ferramentas as que aqui foram utilizadas podem variar de projeto para projeto, de autor para autor, cabendo ao usuário utilizar aquela que mais se adeque ao projeto em questão, entretanto a finalidade da utilização de cada uma delas é a mesma independentemente do projeto.

A base do trabalho foi á aplicação da metodologia Seis Sigma para aumento da disponibilidade física das pás mecânicas Caterpillar 994 do Complexo Mariana, verificou-se que para cada aplicação dessa metodologia existem ferramentas que melhor se adaptam a finalidade do estudo, e cabe aos elaboradores do estudo utilizar aquela que melhor se aplica.

Com base na análise dos dados pode-se concluir que a aplicação da metodologia Seis Sigma para aumento da DF é extremamente eficaz desde que todas as fases citadas sejam cumpridas, fases estas de vital importância para o bom resultado e andamento do projeto.

\section{Agradecimentos}

Agradecemos a Gerência de Manutenção de Equipamentos de Terraplanagem e Carregamento Mariana pela oportunidade de realização desse projeto e em especial a supervisão de manutenção de carregadeiras de grande porte pelo apoio que nos foi dado principalmente para a realização das ações propostas.

O nosso muito obrigado a todos que contribuiram direta ou indiretamente para o sucesso do projeto.

\section{REFERÊNCIAS}

1 Wekerma MCC. Criando a cultura Seis Sigma. Nova Lima: Werkema Editora,2004, $253 \mathrm{p}$.

2 Pande PN, Cavanagh RR. Estratégia Six Sigma: como a GE, a Motorola e outras grandes empresas estão aguçando o seu desempenho. Rio de Janeiro: Qualitymark, 2001.

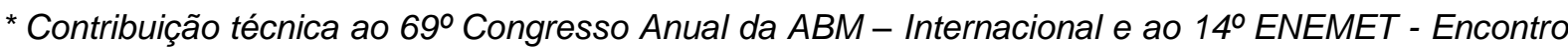
Nacional de Estudantes de Engenharia Metalúrgica, de Materiais e de Minas, 21 a 25 de julho de 2014, São Paulo, SP, Brasil.
} 